\title{
Credible and defensible assessment of entry-level clinical competence: Insights from a modified Delphi study
}

\author{
R. Bacon ${ }^{1}$, L. Williams' ${ }^{2}$ L. Grealish ${ }^{2}$ \& M. Jamieson ${ }^{1}$
}

\begin{abstract}
Background: During clinical placements, supervisors repeatedly assess health and medical students for competence. Quality assessment is dependent upon the supervisors having a rich understanding of entry-level standards and an assessment approach that is sufficiently dynamic to accommodate the changing healthcare system. This study aimed to assess whether consensus could be gained by supervisors when assessing the performance of student dietitians during clinical placements and to establish a shared interpretation of entry-level clinical competence.

Methods: A modified 3-round Delphi study with a focus group discussion was conducted with eight supervisors. Participants were required to assess the performance of student dietitians from audiovisual recordings of authentic student-client consultations in aged-care and outpatient settings.

Results: Consensus was achieved for 2/11 assessments after one Delphi round, 6/11 assessments after two rounds and 10/11 assessments after the third and final round. During the focus group discussion, the expert panel expressed a shared understanding of entry-level performance, however this was not transferred into a shared assessment of entry-level performance in the Delphi task.

Conclusions: Dialogue amongst supervisors leads to a more reliable interpretation of the competency standards. A shared responsibility for assessment, with continuous and open negotiation of meaning, is required to ensure quality assessments of entrylevel practice.
\end{abstract}

Keywords: assessment, clinical placements, Delphi study, competence.

1 University of Canberra

2 Griffith University

Correspondence:

Rachel Bacon

School of Public Health and Nutrition

Faculty of Health

University of Canberra

ACT 2601

Australia

Email: Rachel.Bacon@canberra.edu.au 


\section{Introduction}

Clinical placements assist students to translate theoretical knowledge into practice (Hughes \& Desbrow, 2010) and are a core component of health professional education curricula. In Australia, in the absence of evidence of the time required to attain competence, most accrediting bodies mandate the duration of clinical placements in health professions (National Health Workforce Taskforce, 2008). Student dietitians are required to complete 100 days of field placements, at least half of which are dedicated to developing individual case management or clinical competence, and entry-level competence is assessed by supervisors towards the end of clinical placements (DAA, 2011) based on the DAA (2009) National Entry-level Competency Standards for Australian Dietitians. Unlike some other health disciplines (Dalton, 2009; McAllister, Lincoln, Ferguson, \& McAllister, 2006), dietetics does not have a nationally-validated assessment tool for use by supervisors (Palermo et al., 2014). The assessment tools used to assess competence during clinical placements remain within the purview of the universities (DAA, 2011), but the Dietitians Accreditation Manual states that "primary [placement] supervisors are responsible for verifying the final assessment of competence of students" (DAA, 2011, p. 13). A recent report by the DAA suggested that $10 \%$ of Australian dietetic students are assessed as failing to demonstrate entry-level competence in the allocated timeframe (Williams \& Beck, 2011).

The difficulties inherent in assessing student competence in the workplace are well reported in the literature (Epstein \& Hundert, 2002). Learning occurs within a socio-cultural context, and assessment is influenced by the student's socialisation, the relationship between the student and the supervisor, personal factors and external factors (Levett-Jones, Gresbach, Arthur, \& Roche, 2011). Competency is a human construct and is inherently subjective (Grealish, 2009). Judgement is an inevitable part of assessment, and therefore clinical supervisors need to be supported to make quality judgements, and supervisors need clarity to help them interpret assessment standards and holistic evidence-based assessment processes that consider the learning context (McAllister, Lincoln, \& Ferguson, 2010). Evidence suggests that supervising clinicians have difficulty interpreting and applying the entry-level competency standards when assessing student performance (Lennie \& Juwah, 2010), with a rich understanding of competence supporting quality judgement (McAllister et al., 2010). Johnsson and Hager (2008) found that competency development is dependent on the practice setting, its culture and learning experiences, and this needs to be considered in assessment practices. In addition, global assessments are more reliable (Govaerts, van der Vleuten, \& Schuwirth, 2002), consider intangible competencies (Cox, 2000) and take into account the student's capacity to integrate the units of competency (McAllister et al., 2010) and to transfer competence from one setting to another (Ash $\&$ Phillips, 2000). Resources to support assessments, such as visual representation of entry-level performance, may assist less experienced supervisors with assessments of student-patient encounters (Dalton, 2009). Credible assessments by multiple experts have been facilitated using audiovisual (AV) recordings of clinical encounters (Davies \& 
Clark, 2004). The DAA competency development taskforce used observations by two to six assessors of AV recordings of nutrition counselling sessions in their assessment strategy to evaluate clinical competency development (Ash, 1995).

An approach that supports a shared understanding of entry-level competence that is sufficiently dynamic to accommodate a changing healthcare system is required. Development of such an approach requires qualitative research to explore the assessment process (Govaerts \& van der Vleuten, 2013). This study aimed to use audiovisual (AV) recordings of authentic client consultations to assess whether consensus could be gained by supervisors when assessing the performance of student dietitians during clinical placements and to establish a shared interpretation of entry-level clinical competence.

\section{Method}

A 3-round modified Delphi using online questionnaires interspersed with controlled feedback and a focus group discussion was used to achieve consensus on the global assessments of competence of 11 student/dietitian consultations with clients. These interactions were observed from AV recordings (see Table 1). The Delphi method is a research technique used to establish a consensus of opinion by a panel of experts in order to address a lack of agreement (Powell, 2003). The modified-Delphi method has been used in health and education research to allow participants to make independent assessments without pressure to conform to the opinions of more dominant members (Bowles, 1999). Therefore, it is appropriate to use a modified-Delphi technique that includes a face-toface meeting to enable controversial issues to be elucidated (Brace-Govan, Farrell, Joy, Luxton, \& Davey, 2011). Descriptive statistics are traditionally used in Delphi studies. Median and range are appropriate for ordinal data and expose errors related to outliers (von der Gracht, 2012). The definition of consensus (Table 1) must also align with the Delphi study's purpose and research design (Powell, 2003).

Approval for this study was provided by the University of Canberra Committee for Ethics in Human Research (CEHR 12-209). A reference group with representatives from the health, academic, regulatory, student and consumer sectors was established to provide advice on the direction of the research and ensure its relevance to current practice. Feedback was provided on the scope of the study and the methodology.

In 2012, clinical placement coordinators of the 15 accredited dietetics programs in Australia were approached to nominate credible dietitians with experience and currency of practice in clinical dietetics and student supervision. The nominated supervisors were contacted, via email, and invited to participate in the study. Eight supervisors, representing all states/territories with accredited programs, participated in the research after providing written consent and receiving a small honorarium.

Eleven purpose-developed AV recordings of authentic student or dietitian consultations with clients were recorded. The consultations in this study occurred within a studentled university clinic that provided outpatient clinics and outreach services to aged-care facilities. Unobtrusive AV recording is part of the regular teaching practices within these clinics, and written consent was obtained from all people recorded, with minimal editing performed to decrease the time taken to view the recordings, while preserving 


\section{ASSESSMENT OF CLINICAL COMPETENCE}

Table 1

The Modified-Delphi Study

\section{Round 1 (4 weeks)}

\begin{tabular}{|c|c|c|c|}
\hline \multicolumn{4}{|c|}{ Round 1 (4 weeks) } \\
\hline Method & \multicolumn{3}{|c|}{$\begin{array}{l}\text { Supervisors independently assessed each AV recording using the assessment processes } \\
\text { they routinely used then completed the research assessment questionnaire. }\end{array}$} \\
\hline \multirow[t]{2}{*}{ Analysis } & \multicolumn{3}{|c|}{$\begin{array}{l}\text { VAS ratings were recorded as raw scores. } \\
\text { Consensus was achieved when all ratings fell within a 3-point range. } \\
\text { RB used thematic analysis to synthesis the qualitative comments in Round } 1 .\end{array}$} \\
\hline & $\begin{array}{l}\text { For opinion responses: } \\
\text { Themes were listed. }\end{array}$ & $\begin{array}{l}\text { For justification responses: } \\
\text { Themes were categorised } \\
\text { into qualifiers, reinforcers } \\
\text { and negators. }\end{array}$ & $\begin{array}{l}\text { For descriptive responses: } \\
\text { Low inference descriptions } \\
\text { were used to capture the } \\
\text { tone of the responses. }\end{array}$ \\
\hline
\end{tabular}

Feedback $\quad$ RB prepared a summary report for each AV recording that was provided to participants prior to completing Round 2.

\section{Round 2 (4 weeks)}

\begin{tabular}{ll} 
Method & $\begin{array}{l}\text { Supervisors revised their global assessments for the students' performance where } \\
\text { consensus had not been reached. }\end{array}$ \\
Analysis & Quantitative data was analysed on Qualtrics using descriptive statistics (median, range). \\
\hline Method & Focus Group \\
& A structured protocol informed by Round 2 considered inconsistencies in assessments \\
& where consensus had not been achieved. \\
& The expert panels' experience with the research assessment questionnaire was explored. \\
& The discussion was audiotaped and transcribed. \\
Analysis & RB and the scribe independently prepared a summary report with consensus in the two \\
& reports achieved. \\
& Thematic analysis was later conducted on the transcript using van Manen's (1984) \\
highlighting approach. & Transcripts were analysed independently by RB and the research assistant. \\
Panel & Participants were provided with the results from Round 2. \\
feedback & A summary of the focus group discussion was provided to participants.
\end{tabular}

\section{Round 3 (2 weeks)}

Method Supervisors revised their original global assessment when consensus had not been reached and provided a global assessment of an additional AV recording of a new graduate consultation. Related extracts of the client's medical notes and/or footage from the AV recordings were embedded in the survey, providing evidence to assist supervisors in their assessments. Qualitative questions were also included that sought further clarification in regard to entry-level performance.

Demographic data about the expert panel was also collected.

Analysis $\quad$ Quantitative analysis (as per Round 1):

Thematic analysis was used to analyse the qualitative responses using van Manen's (1984) highlighting approach.

Responses were analysed independently by RB and the research assistant.

Themes across all three rounds were pooled and reported together.

Direct quotes were used as data to support the identified themes. 
the authenticity of the consultations. Nine of the consultations were in the primary-care setting and two were in the aged-care setting. Eight were initial consultations and two were reviews. Three students appeared in more than one AV recording. The topics of the consultations represented a varied case-mix, including malnutrition, overweight/obesity, nutritional adequacy (vegan diet), sports nutrition, food intolerance, hypercholesterolemia, diabetes and oncology (see Table 2). Seven students were recorded during Weeks 1-5 of their clinical placement and two in Weeks 6-10. Two practitioners, one a recent graduate and the other with five years' experience, were also recorded in the same setting. These recordings were made available to the supervisors for the duration of the study via a password protected private website. All recordings were deliberately presented to the supervisors as student-led consultations, with the consultations with qualified dietitians deliberately included to provide a validity check of the ratings.

Table 2

Global Ratings of Student Performances

\begin{tabular}{|c|c|c|c|c|c|c|c|}
\hline \multirow{2}{*}{$\begin{array}{l}\text { AV } \\
\text { recording } \\
\text { number }\end{array}$} & \multirow[b]{2}{*}{ Placement } & \multirow[b]{2}{*}{ Settings } & \multirow[b]{2}{*}{ Case type } & \multirow[b]{2}{*}{$\begin{array}{l}\text { Consultation } \\
\text { type }\end{array}$} & Round 1 & Round 2 & Round 3 \\
\hline & & & & & \multicolumn{3}{|c|}{$\begin{array}{l}\text { VAS scores: Raw (non-consensus) } \\
\text { or range } \& \text { median (consensus) }\end{array}$} \\
\hline AV 5 & $\begin{array}{l}\text { Weeks } \\
1-5\end{array}$ & $\begin{array}{l}\text { Outpatient } \\
\text { clinic }\end{array}$ & Obesity & Initial & $\begin{array}{l}1,1,2,2,3 \\
3,4,6\end{array}$ & $\begin{array}{l}\text { Range 1-3 } \\
\text { Median } 2\end{array}$ & \\
\hline AV 9 & $\begin{array}{l}\text { Weeks } \\
1-5\end{array}$ & $\begin{array}{l}\text { Outpatient } \\
\text { clinic }\end{array}$ & Oncology & Initial & $\begin{array}{l}2,2,3,3,4 \\
4,5,6\end{array}$ & $\begin{array}{l}\text { Range 2-4 } \\
\text { Median } 3\end{array}$ & \\
\hline AV 1 & $\begin{array}{l}\text { Weeks } \\
6-10\end{array}$ & $\begin{array}{l}\text { Outpatient } \\
\text { clinic }\end{array}$ & $\begin{array}{l}\text { Sports nutrition } \\
\text { (clinically complex) }\end{array}$ & Initial & $\begin{array}{l}2,3,4,4,5 \\
6,6,7\end{array}$ & $\begin{array}{l}3,3,3,4,5 \\
5,6,7+\end{array}$ & $\begin{array}{l}\text { Range 4-6 } \\
\text { Median } 4\end{array}$ \\
\hline AV 7 & $\begin{array}{l}\text { Weeks } \\
6-10\end{array}$ & $\begin{array}{l}\text { Outpatient } \\
\text { clinic }\end{array}$ & $\begin{array}{l}\text { Vegan diet } \\
\text { (socially complex) }\end{array}$ & Initial & $\begin{array}{l}4,4,4,5,5 \\
7,7^{*}\end{array}$ & $\begin{array}{l}\text { Range 4-6 } \\
\text { Median } 5\end{array}$ & \\
\hline AV 2 & $\begin{array}{l}\text { Weeks } \\
1-5\end{array}$ & $\begin{array}{l}\text { Outpatient } \\
\text { clinic }\end{array}$ & Diabetes (Type 2) & Initial & $\begin{array}{l}1,1,2,3,4 \\
5,7,7+\end{array}$ & $\begin{array}{l}2,3,3,3,3 \\
4,4,6\end{array}$ & \begin{tabular}{|l|} 
Range 4-6 \\
Median 4.5
\end{tabular} \\
\hline AV 4 & $\begin{array}{l}\text { Weeks } \\
6-10\end{array}$ & Aged care & $\begin{array}{l}\text { Malnutrition/ } \\
\text { Diabetes }\end{array}$ & Review & $\begin{array}{l}4,5,6,6,7 \\
7,7,7\end{array}$ & $\begin{array}{l}4,5,5,6,6 \\
6,7,7\end{array}$ & $\begin{array}{l}\text { Range 5-7 } \\
\text { Median } 6\end{array}$ \\
\hline AV 3 & $\begin{array}{l}\text { Weeks } \\
1-5\end{array}$ & Aged care & $\begin{array}{l}\text { Malnutrition/ } \\
\text { Diabetes }\end{array}$ & Review & $\begin{array}{l}4,4,6,6,7 \\
7+, 7+\end{array}$ & $\begin{array}{l}\text { Range 5-7 } \\
\text { Median } 5.5\end{array}$ & \\
\hline AV 8 & $\begin{array}{l}\text { Weeks } \\
6-10\end{array}$ & $\begin{array}{l}\text { Outpatient } \\
\text { clinic }\end{array}$ & $\begin{array}{l}\text { Food-Intolerance } \\
\text { (clinically complex) }\end{array}$ & Initial & $\begin{array}{l}4,4,5,6,7 \\
7,7,7+\end{array}$ & $\left|\begin{array}{l}4,5,5,5,6 \\
7,7,7\end{array}\right|$ & $\begin{array}{l}4,5,6,6,6,7 \\
\text { No consensus }\end{array}$ \\
\hline AV 10 & $\begin{array}{l}\text { Weeks } \\
6-10\end{array}$ & $\begin{array}{l}\text { Outpatient } \\
\text { clinic }\end{array}$ & $\begin{array}{l}\text { Hypercholesterol- } \\
\text { emia/Overweight }\end{array}$ & Initial & $\begin{array}{l}4,5,6,6,6 \\
6,7,7\end{array}$ & $\begin{array}{l}\text { Range 5-7 } \\
\text { Median } 6\end{array}$ & \\
\hline AV 11 & $\begin{array}{l}\text { New } \\
\text { graduate } \\
\text { dietitian }\end{array}$ & $\begin{array}{l}\text { Outpatient } \\
\text { clinic }\end{array}$ & Overweight & Initial & $\begin{array}{l}\text { Range 7-7+ } \\
\text { Median 7+ }\end{array}$ & & \\
\hline AV 6 & $\begin{array}{l}\text { Experienced } \\
\text { dietitian }\end{array}$ & $\begin{array}{l}\text { Outpatient } \\
\text { clinic }\end{array}$ & $\begin{array}{l}\text { Obesity/ } \\
\text { Depression }\end{array}$ & Initial & $\begin{array}{l}\text { Range 7-7+ } \\
\text { Median 7+ }\end{array}$ & & \\
\hline
\end{tabular}

* Only 7 responses were recorded for these surveys 
The theoretical construct for competency-based assessment in dietetics (Ash \& Phillips, 2000) is based on Dreyfus and Dreyfus' (1980) model of skills applied to the health context by Benner (1984). This model presents competence as part of a continuum of learning from novice to expert rather than as an end-point of competent or not yet competent (Ling, 1999). The DAA National Standards for Entry-level Competence describe the job roles of dietitians and are intended to be assessed together as an integrated whole using practice tasks rather than as a check list of functional skills that must be demonstrated (Ash \& Phillips, 2000).

In a previous study, no validated clinical dietetic competence tool was identified for use by clinical supervisors (Bacon, Williams, \& Grealish, 2014). A questionnaire to assess the students/dietitians performance was therefore developed based on Unit 4 of the National Competency Standards for Entry-level Dietitians (DAA, 2009), which details the eight individual case management elements of competencies (Figure 1) and the behavioural descriptors (Figure 2) used in speech pathology by McAllister et al. (2006). The behavioural descriptors support competency-based assessments that consider the practice setting, the

Please enter your GLOBAL RATING ${ }^{2}$ the student's overall competency with consideration to Unit 4 - Manages client-centred nutrition care of individuals.

Please consider the related elements of competency listed below and the Behavioural descriptors provided in round 1 before making your decision.

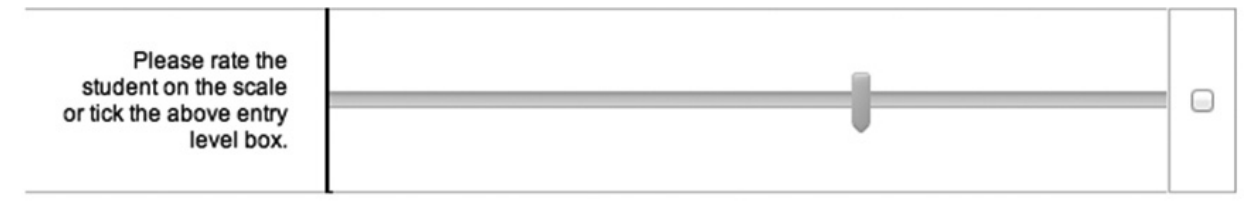

\section{Elements of competency:}

4.1 Undertakes screening and assessment to identify and prioritise those at nutritional risk.

4.2 Determines nutritional status using assessment data.

4.3 Makes appropriate nutrition diagnosis.

4.4 Prepares plan for achieving management goals in collaboration with client or carer and other members of the health care team.

4.5 Uses client centred counselling skills to facilitate nutrition and lifestyle changes and support client to self manage

4.6 Implements nutrition plan in collaboration with client or carer and other members of the health care team. 4.7 Monitors progress of the individual's condition and care and adopts plan as necessary.

4.8 Documents and communicates all steps in the process.

* The behavioural descriptors included above are described in Figure 2.

Figure 1. Global assessment of competency use for assessment questionnaire. 


\section{BEHAVIOURAL DESCRIPTORS OF STUDENT COMPETENCY ${ }^{\top}$}

\section{Novice Student}

- High degree of supervisory support

- Saa recall some aspects of relevant theory

- Needs support to:

- Drow conclusions about a client

- Develop a plan for oction

- Understand the total clinical situation

- Apple pcobleca solviog strategies priosiples and theocx.

- Speodis a high degree of time and effort in meeting cínical responsiblilies

- Highly focused on own performance rather than the clent.

\section{Intermediate Student}

The complexity of the client, the workploce environment and the student's previous experience determines:

- Degree of supervision (moderate to low)

- Ablitx to recogolse the meaningefulaspectsofosituation.

Recognises several aspects of a problem but not all, and relates these to the client's needs and is able to:

- Draw some accurate conclusions about a client

- Develop some plans for action

- Recognise some important aspects of the total clinical situation.

Requires support to:

- Recognise and prioritise all aspects of a situation

- Flexibly apply problem solving strategies, principles and theory.

Developing automaticity resulting in:

- A moderate expenditure of time and effort

- Greater ablity to focus on the situation than on own performance

- A developing ablity to use observation to assist clinical reasoning.

\section{Entry-level (Competent) Student}

The student is oble to

- Perform the mojority of his/her work independently and competently

- Seek support if the situation is new or a number of features about the client or workplace setting combine to create complexity

- ideatify the meaningful aspects of problems and integrate these to generate o number oflogically possible conclusions. Conclusions/actions will be modified with new information

- Prioritise oppropriately

- Be sufficiently automatic and maintain a focus on the client or situation

- Comy out his/her work in an efficient and timely manner.

1 Usestwwith permiseion from Speoch Pathology Australia. Source: MeNlister, S. M. Lincoln, Forguson, A. \& McNlister, L (2006). COMPNSS8: Competency assossment in spoech pathology. LobocuesemSpeach Patbolbesc Asecsiationast Austobliobd.

Figure 2. Behavioural descriptors of student competency. 
complexity of the client and the student's level of experience. These descriptors inform the visual analogue scale (VAS) and have been previously shown to rate performance in a predictable manner (McAllister, Lincoln, Ferguson, \& McAllister, 2011).

The questionnaire developed for this study included: (1) a VAS and a qualitative description providing a global assessment of performance (Figure 1), (2) a VAS item and qualitative description of performance for each element of competency within Unit 4, (3) a description of entry-level performance for each element within Unit 4, (4) feedback to the student about their performance in the client consultations and (5) strategies to support the student's learning. The reference group and two academics with expertise in health professional competency-based assessment were consulted in the development of the questionnaire, and the questionnaire was pilot-tested with two clinical educators to test for readability, clarity of instruction and face validity, and minor modifications were made. Round 1 of the modified Delphi commenced in February 2013. The supervisors used the questionnaire online through the private website. Details of the modified-Delphi study, including method, data analysis and panel feedback, are provided in Table 1.

\section{Results}

Five out of eight supervisors had more than 10 years' experience as a dietitian and more than six years' experience in supervising students on clinical placements. Four supervisors had experience of working in an outpatient setting, but only two supervisors had worked in a residential aged-care facility. All eight supervisors participated in Round 1, Round 2 and the focus group, and seven participated in Round 3. Table 2 shows the VAS ratings by each supervisor for each student/dietitian's performance over the three rounds of the modified-Delphi study. Although the data was analysed to explore patterns in the VAS scores based on assessor characteristics, no significant findings emerged.

Three themes emerged from the qualitative data: (1) the qualitative descriptions made by the clinical supervisors in Round 1 reflected the same variation evident in the VAS scores; (2) through the Delphi process, supervisors' assumptions, observations and the influence of their experience became apparent; and (3) the Delphi process enabled supervisors to gain a shared understanding of entry-level competence.

\section{Theme 1: Qualitative descriptions in Round 1 reflected the variation in VAS scores}

The global qualitative descriptions for individual students' performances in Round 1 varied considerably between assessors, reflecting the variations found between the VAS scores. The following two comments were made about AV Recording 2 of a student in clinical weeks $1-5$ by a supervisor who gave a VAS rating of 1 and another supervisor who gave a rating of 7 , respectively.

Didn't build rapport. Lacked confidence and clarity with data collection. Left long pauses while writing notes. Took a long time to collect data, particularly diet history, was not concise. Did not give a good clear assessment of patient. Good to test patient's prior knowledge of diabetes. Diet-disease relationship not all that clear (although good 
attempt) and did not educate patient on ideal. Did come up with appropriate goal of CHO [Carbohydrate] distribution rather than GI [glycaemic index] but not clearly expressed to patient so patient lacked understanding and therefore objected to suggestions. Didn't use resources. (Supervisor 8, Delphi Round 1)

I think this student did well. The interview was very long, and I think with more experience could have easily been shortened (redirecting client and not going into so much detail in the checklist); overall was done well. (Supervisor 1, Delphi Round 1)

\section{Theme 2: Through Delphi process supervisors' assumptions, observations, and the influence of their experience became apparent}

Supervisors made different assumptions about when to assess student's competence. One supervisor felt that although complex cases were good for student learning, such cases did not provide a suitable context to assess entry-level performance:

I think it is great practice. I mean, if that was a day you were choosing to do an assessment, you might at the end say let's not use that one because it is so challenging on a number of levels and it's still good skills. (Supervisor 6, focus group)

Another supervisor commented that the behavioural descriptors given as part of the VAS rating system were helpful for complex cases, to interpret student performance in light of the context:

I used it especially for some of those people when I wasn't sure they were entry-level intermediate. I went back to the criteria and used the criteria to decide. (Supervisor 5, focus group)

In their qualitative comments, some supervisors focused on the details that needed improvement, such as this comment by a supervisor who gave a VAS rating of 6 for the performance of a student in weeks $1-5$ of their placement, whereas another supervisor focused on the key outcomes achieved by the student in the same consultation and gave a VAS rating of 7. The supervisor who gave the VAS rating of 6 commented:

I thought the student needed to improve the commencement of the interview-building rapport and communication style ... She needed to quantify the weight loss, do an SGA and identify a weight goal. (AV 3, supervisor 4, Delphi Round 3)

The other supervisor noted:

She demonstrated the ability to use client counselling; she implemented change in collaboration with the client; she drew justifiable conclusions from the data, and she was clear, concise and appropriate with the client. I feel she was at entry-level. (AV 3, supervisor 3, Delphi Round 3)

Consideration of the practice setting influenced the qualitative descriptions made by the supervisors. The following focus group comment was about an encounter in the aged-care setting. 
She gave her a fairly clear assessment ... like, your weight is stable so it looks like you are eating enough, and your BGLs [blood glucose levels] are well controlled so considering your age and that you are in an aged-care facility, keep doing what you're doing. (AV 4, supervisor 8 , focus group)

In the focus group, supervisors reported that their assessments were influenced by the observations of others in the feedback report.

I actually didn't notice that until I read your comment, so I watched it again and I thought she said she had a breast cancer and she has lost weight since then. (AV4, supervisor 4 , focus group)

The supervisors' professional experience influenced their assessments.

Well, it was me who wrote down the breast cancer thing [qualitative description, Delphi Round 1] ... I don't know and it was a bit unclear and I guess for me I work in oncology at the moment so I wanted that followed up a bit more. (AV 4, supervisor 7, focus group)

During the focus group, supervisors reflected on the influence of their personal experiences and self-awareness of their own development since graduation.

I think it is important to remember that these are entry-level practitioners, and they should not be expected to be perfect or like us. (Supervisor 6, focus group)

\section{Theme 3: The Delphi process supported a shared understanding of entry-level competence}

In Round 1 of the modified Delphi, supervisors referred to the Unit 4 performance criteria to provide their qualitative descriptions of entry-level performance in clinical dietetics. In the focus group discussion, the supervisors expressed a common understanding of describing entry-level performance in global terms that included a demonstration of the dietetic process, an understanding of their scope of practice and the capacity for self-reflection and lifelong learning. However, supervisors in the focus group questioned their ability to clearly assess attainment of entry-level performance in actual clinical encounters.

You might get a placement where you are doing lots of oncology, or you might get renal and get good at that. I think you just need the skills in how to keep learning. (Supervisor 7, focus group)

I think what is tricky is the standard to which we expect them to do these things. I mean, I agree I think we expect they show some ability to do all of them [the performance criteria], but where is that grey line ... At entry-level, I would have known the basics, but how do we define it? (Supervisor 6, focus group).

Table 3 shows the qualities the supervisors' described in their written comments in Round 3 of the Delphi, when asked to discern whether a student was at entry-level. 
Table 3

Qualities Used by Supervisors to Discern Entry-level Performance

\begin{tabular}{|c|c|c|}
\hline Stage of development & Approaching entry-level & Entry-level \\
\hline \multirow[t]{6}{*}{$\begin{array}{l}\text { Qualities evident in the } \\
\text { student's performance }\end{array}$} & $\begin{array}{l}\text { Completes the majority of the work } \\
\text { independently and competently. } \\
\text { Demonstrates professionalism. }\end{array}$ & $\begin{array}{l}\text { Safe, professional and independent. } \\
\text { Able to work within their scope } \\
\text { of practice. }\end{array}$ \\
\hline & $\begin{array}{l}\text { Collects meaningful data but } \\
\text { lacks detail. }\end{array}$ & $\begin{array}{l}\text { Provides comprehensive data } \\
\text { collection—qualified and quantified. }\end{array}$ \\
\hline & $\begin{array}{l}\text { Provides an accurate and safe } \\
\text { assessment but lacks clarity. }\end{array}$ & $\begin{array}{l}\text { Provides qualitative and } \\
\text { quantitative assessment. }\end{array}$ \\
\hline & $\begin{array}{l}\text { The student negotiates appropriate } \\
\text { goals but these need to be more specific } \\
\text { and measurable. }\end{array}$ & $\begin{array}{l}\text { Negotiates clear goals and a } \\
\text { specific plan. }\end{array}$ \\
\hline & $\begin{array}{l}\text { Provides appropriate advice but needs to } \\
\text { improve the structure and organisation of } \\
\text { the education. }\end{array}$ & Great flow and structure. \\
\hline & Uses client-centred counselling skills. & $\begin{array}{l}\text { Uses client-centred counselling skills } \\
\text { and individualised education, and } \\
\text { motivates the client. }\end{array}$ \\
\hline
\end{tabular}

\section{Discussion}

This research provides insight into the way that supervisors assess whether students demonstrate clinical competencies in client consultations. After the first round of the modified-Delphi study, there was little consistency in the assessment ratings or descriptions made by supervisors about the performances of the student dietitians. This variation in assessments is consistent with other studies of work-based assessment that report low interrater reliability (Albanese, 2000). By the end of the third round, however, the supervisors had achieved consensus in their assessments of all but one of the consultations, where the scores ranged from 4 to 7 (from a maximum score of 7 or above).

This research has resulted in a shared conceptual understanding of entry-level competence amongst the supervisors. They agreed that, at entry-level, the students should be able to recognise the scope of practice in which they were able to provide dietetic care comprehensively and with clarity. The supervisors supported the use of the behavioural descriptors and the VAS scale system when making their assessment of performance. In fact, all supervisors assessed the two qualified dietitians' performance in the client consultations as entry-level or above in the first modified-Delphi round, providing a measure of validity to the assessment instrument used in the study.

The supervisors' theoretical understanding of entry-level performance, however, was applied inconsistently when assessing the students' performance in client consultations. As a panel, the supervisors struggled to identify the point at which a student reach "entry-level". This is not surprising as the development of competence is a journey, not a destination, and entry-level marks a grey-line in development between the stages 
of beginner (labeled intermediate in McAllister el al. (2006) behavioural descriptor system) and competent (Benner, 1984). Given that 10\% of students fail to reach clinical competence, this research raises concerns about the fairness of current assessment processes (Williams \& Beck, 2010). Credible and defensible assessment processes may help to minimise the inconsistency in supervisors' judgements of entry-level.

In this study, the sharing of assessments and dialogue between supervisors supported them in reaching consensus in their assessments. The AV recordings used in this study provide visual representations of performance. Visual representations can be used by less experienced supervisors to gain an understanding of expected standards of performance during placement (Dalton, Keating, \& Davidson, 2009). Through the modified-Delphi process, supervisors identified and clarified assumptions and learned from the observations and experience of one another. A heightened awareness of the influence of their own experience and expertise on their judgement became apparent. This is consistent with the constructivist-interpretivist approach towards work-based assessments proposed by Govaerts and van der Vleuten (2013), where they advocate for an "interpretive community" where supervisors are able to articulate their own values and assumptions underlying their judgements, engage in critical dialogue and reconsider their assessments in the light of these negotiations.

The methods used in this study are robust. Supervisors' assessments of students' performance during clinical placements are highly valued in practice for determining a student's readiness to enter the profession (McAllister et al., 2011). Global assessments (Chapman, 1998; Cox, 2000; Govaert et al., 2002) by multiple assessors (Davies \& Clark, 2004) are seen as supporting quality assessments, and authentic assessments are considered the "gold standard" for determining competency to practise (Eraut, 1994; McKinley, Fraser, \& Baker, 2001). By incorporating the previously validated behavioural descriptors and VAS scales developed by McAllister et al. (2006), the learning context was considered. The assessment process was validated by the assessment of the dietitians' performance, with the reference group providing expertise and incorporating the perspectives of key stakeholders. The credibility of the study was improved by providing detail on the selection of supervisors, data collection procedures and identification of consensus level (Powell, 2003). The supervisors were nationally representative, and the independent nomination of expert assessors attributed credibility to participant selection. The use of eight assessors of a student's performance is considered rigorous in comparison to similar research studies (Ash, 1995).

This research is limited by assessments being made based on a single observable performance for some students rather than multiple sources of evidence across the duration of the placement (Schuwirth \& van der Vleuten, 2003). The panel of supervisors agreed that the use of AV recorded consultations provided insufficient evidence to assess the element of competency 4.8-documents and communicates all steps of the process. In addition, the Delphi approach has been criticised as providing a normative rather than an informational influence (von der Gracht, 2012). These results should, therefore, be interpreted as offering an expert opinion rather than indisputable fact. No prerequisite requirement for any formal education in assessment was mandated for participation. 
More evidence is required to support the use of assessment panels during clinical placements and the value of a professional interpretive community to gain a shared understanding of entry-level performance. Further research may also consider the career implications of clinical placement assessments. How does a "failed" clinical placement impact on the student? For instance, is their assessment outcome reflective of their later contribution to the health profession?

\section{Conclusion}

This paper highlights the issues of judgment and subjectivity in the assessment of health professional competence. It acknowledges how interpretation of student performance is influenced by observations, experience and assumptions. It also contributes evidence to reframe clinical assessments, moving away from notions of objectivity, reliability and validity towards notions of credibility and defensibility.

There is value in considering the role of panels in the assessment of student competence during clinical placements. The supervisors in this study were generally able to reach consensus in their assessments and move towards a shared understanding of entry-level performance through dialogue. Credentialing agencies should call for regular comparison meetings of placement assessors within tertiary programs and across accredited university programs to ensure the fairest and highest quality assessment of entry-level performance.

\section{Statement of Reflexivity}

The qualitative research included in this paper considers the lived experiences of the participants. To ensure a robust research design the influence of the researcher on the data collection and interpretation must be considered. Reflexivity requires selfawareness by the researchers of their own experience and perspectives (Yin, 2011).

I (RB) am an academic in a Masters of Nutrition and Dietetics program. In this role, I am responsible for the clinical placement program, including the establishment of the student-led dietetics clinics where the consultations were recorded for this study. Prior to my appointment, I worked as a dietitian for 15 years, predominantly in the clinical field, and for the last seven years specifically in clinical education. I know all the students and some of the dietitians who were participants in this study. Therefore, there is a risk of subjectivity in data collection and interpretation. Understanding this risk, I have taken care to ensure the results have been independently verified. It is only by accurately understanding the experiences of the participants that I could gain sufficient insight to assist supervisors to achieve more credible and defensible assessments, therefore, ultimately benefiting our students and the profession.

\section{Acknowledgements}

We would like to thank the participants, the reference group and Amy Haughey for her contribution as a research assistant.

This research was made possible due to funding from Health Workforce Australia, an Australian Government Initiative, as part of the 2012 National Clinical Supervision Fellowship Initiative. This research is supported by the University of Canberra as part of a doctoral thesis. 
ASSESSMENT OF CLINICAL COMPETENCE

\section{References}

Albanese, M. (2000). Challenges in using rating judgements in medical education. Journal of Evaluation of Clinical Practice, 6(3), 305-319.

Academy of Nutrition and Dietetics. (2013). Revised 2012 standards of practice in nutrition care and standards of professional performance for registered dietitians. Journal of the Academy of Nutrition \& Dietetics, 113(6), s29-s45.

Ash, S. (1995). The development of an assessment strategy related to the Dietitian's National Competency Standards. Canberra, Australia: Dieticians Association of Australia.

Ash, S., Dowding, K., \& Phillips, S. (2010). Mixed methods research approach to the development and review of competency standards for dietitians. Nutrition \& Dietetics, 68(4), 305-315.

Ash, S., \& Phillips, S. (2000). What is dietetic competence? Competency standards, competence and competency explained. Australian Journal of Nutrition \& Dietetics, 57(3), 147-151.

Bacon, R., Williams, L., \& Grealish, L. (2015). Aged care facilities and primary healthcare clinics provide appropriate settings for dietetic students to demonstrate individual case management clinical competence. Nutrition \& Dietetics, 72(1), 54-62.

Benner, P. (1984). From novice to expert: Excellence and power in clinical nursing practice. Menlo Park, CA: Addison-Wesley Publishing Company.

Bowles, N. (1999). The Delphi technique. Nursing Standard, 45(13), 32-36.

Brace-Govan, J., Farrell, S., Joy, S., Luxton, S., \& Davey, I. (2001). Delphi revisited: A concise method for industry consultation on curriculum. Australian New Zealand Journal of Vocational Education Research, 9(1), 1-19.

Chapman, J. (1998). Agonising about assessment. In D. Fish \& C. Colin (Eds.), Developing professional judgement in health care: Learning through the critical appreciation of practice (pp. 157-181). Boston, MA: Butterworth-Heineman.

Cox, K. (2000). Examining and recording clinical performance: A critique and some recommendations. Education and Health, 13(1), 44-54.

Dalton, M. (2009). Development of the clinical assessment of physiotherapy skills (CAPS): A standardised and valid approach to assessment of clinical competence in physiotherapy. Brisbane, Australia: Australian Learning and Teaching Council.

Dalton, M., Keating, J., \& Davidson, M. (2009). The assessment of physiotherapy (APA) instrument clinical educator resource manual. Melbourne, Australia: Australian Learning and Teaching Council.

Davies, J., \& Clarke, D. (2004). Clinical skills acquisition in children's nursing: An international perspective. Paediatric Nursing, 16(2), 23-26.

Dietitians Association of Australia (DAA). (2011). Manual for accreditation of dietetics education programs Version 1.2 (October 2011). Canberra, Australia: Author.

Dietitians Association of Australia (DAA). (2009). National competency standards for entry-level dietitians in Australia. Canberra, Australia: Author. 
Dreyfus, H., \& Dreyfus, S. (1980). A five-stage model of the mental activities involved in direct skills acquisition. Washington, DC: Storming Media.

Epstein, R., \& Hundert, E. (2002). Defining and assessing professional competence. Journal of the American Medical Association, 287(2), 226-235.

Eraut, M. (1994). Developing professional knowledge and competence. London, England: The Falmer Press.

Govaerts, M., \& van der Vleuten, C. (2013). Validity in work-based assessment: Expanding our horizons. Medical Education, 47, 1164-1174.

Govaerts M, van der Vleuten C, \& Schuwirth L. (2002). Optimising the reproducibility of a performance-based test in midwifery education. Advances in Health Science Education, 7, 133-145.

Grealish, L. (2009). Crafting competence: The governance of multiplicity in nursing. Unpublished doctoral dissertation, University of Canberra-Canberra, Australia.

Hughes, R., \& Desbrow, B. (2010). An evaluation of clinical dietetics student placement case-mix exposure, service delivery and supervisory burden. Nutrition \& Dietetics, 67(4), 287-293.

Johnsson, M., \& Hager, P. (2008). Navigating the wilderness of becoming professional. Journal of Workplace Learning, 20(7), 526-536.

Lennie, S., \& Juwah, C. (2010). Exploring assessment for learning during dietetics practice placements. Nutrition \& Dietetics, 23(3), 217-223.

Levett-Jones, T., Gresbach, J., Arthur, C., \& Roche, J. (2011). Implementing a clinical competency assessment model that promotes critical reflection and ensures nursing graduates' readiness for professional practice. Nurse Education in Practice, 11(1), 64-69.

Ling, P. (1999, July). Assessing competency. Paper presented at the HERDSA Annual International Conference, Melbourne, Australia.

National Health Workforce Taskforce. (2008). Data, capacity and clinical placements across Australia: A discussion paper. Canberra, Australia: Author.

McAllister, S., Lincoln, M., \& Ferguson, A. (2010). Issues in developing valid assessments of speech pathology students' performance in the workplace. International Journal of Language Communciation Disorders, 45(1), 1-14.

McAllister, S., Lincoln, M., Ferguson, A., \& McAllister, L. (2011). A systematic program of research: The assessment of speech-language pathology competencies. International Journal of Speech Language Pathology, 13(6), 469-479.

McAllister, S., Lincoln, M., Ferguson, A., \& McAllister, L. (2006). Competency assessment in speech pathology. Melbourne, Australia: Speech Pathology of Australia.

McKinley, R., Fraser, R., \& Baker, R. (2001). Model of directly assessing and improving competence and performance in revalidation of clinicians. British Medical Journal, 322, 721-714. 


\section{ASSESSMENT OF CLINICAL COMPETENCE}

Palermo, C., Capra, S., Ash, S., Beck, E., Truby, H., \& Jolly, B. (2014). Professional competence standards, learning outcomes and assessment: Designing a valid strategy for nutrition and dietetics. Sydney, Australia: Office for Learning and Teaching, Australian Government.

Powell, C. (2003). The Delphi technique: Myths and realities. Journal of Advanced Nursing, 41(4), 376-382.

Schuwirth, L. V., \& van der Vleuten, C. (2003). ABC of learning and teaching in medicine: Written assessments. British Medical Journal, 326, 643-645.

van Manen, M. (1984). Practising phenomenological writing. Phenomenology \& Pedagogy, 2(1), 36-68.

von der Gracht, H. (2012). Consensus measurement in Delphi studies: Review and implications for future quality assurance. Technological Forecasting and Social Change, 79(7), 1525-1536.

Williams, P., \& Beck, E. (2011). Final report on Simulated Learning Environment Project conducted for Health Workforce Australia. Canberra, Australia: Dietitians Association of Australia.

Yin, R. (2011). Qualitative research from start to finish. New York, NY: Guilford Press. 